\title{
Evaluating Cross-blended Hypsometric Tints: \\ A User Study in the United States, Switzerland, and Germany
}

\author{
Tom Patterson \\ National Park Service \\ tom_patterson@nps.gov
}

Bernhard Jenny

Oregon State University

jennyb@geo.oregonstate.edu

\section{ABSTRACT}

Cross-blended hypsometric tints display elevation while locally adjusting colors to match the differing natural environments of world regions. This paper presents the results of a study comparing cross-blended hypsometric tints with conventional hypsometric tints. Over 200 respondents in the United States, Switzerland, and Germany were asked to interpret the meaning of color on both types of hypsometric maps. The study revealed significant differences between map readers in the United States and the two European countries, and a general difficulty in correctly interpreting hypsometric colors. Most participants perceived hypsometric tints as representing both topography (elevation and land forms) and environmental phenomena.

KEYWORDS: cross-blended hypsometric tints; user survey; color perception

\section{INTRODUCTION}

Cross-blended hypsometric tints are a new type of elevation coloring for maps introduced in this journal (Patterson and Jenny 2011) that employ variable lowland colors customized to match the differing natural environments of world regions. A notable trait is the absence of green from arid lowlands, which is typical of traditional hypsometric tints.

A free raster dataset with cross-blended hypsometric tints is available on the NaturalEarthData.com website (Patterson and Kelso 2009). In the three years since becoming available, these tints have proven popular among mapmakers, with more than 100,000 downloads. Despite their widespread use, however, a basic question remains: are cross-blended hypsometric tints more understandable to readers than the conventional tints that they are intended to replace? The user study discussed in the following pages attempts to answer this question.

Starting in the mid-1800s in Austria (Kretschmer 1986; 1988), cartographers have used a variety of sequential colors to depict elevation zones on maps, typically starting with green lowlands that change to yellow, beige, brown, red, or white in layered steps as elevation increases (see Patterson and Jenny [2011] for an overview). Later developments included hypsometric tints with shaded relief and depicting tints as gradients that continuously blend together rather than exist in discrete layers. Hypsometric tinting has become a de facto standard for small-scale physical maps found in atlases, on classroom walls, and in tourist publications.

Cross-blended hypsometric tints are very much like those described above but with a major difference: the lowland color varies depending on the natural environment of the region being depicted. For example humid lowlands with plentiful vegetation are shown in green-similar to a map with conventional hypsometric tints. Cross-blended hypsometric tints, however, depict arid lowlands with brown and polar lowlands with gray blue. In addition, the green tint in humid lowlands varies. Sub-arctic lowlands, such as western Siberia, appear as cold blue green, and tropical 


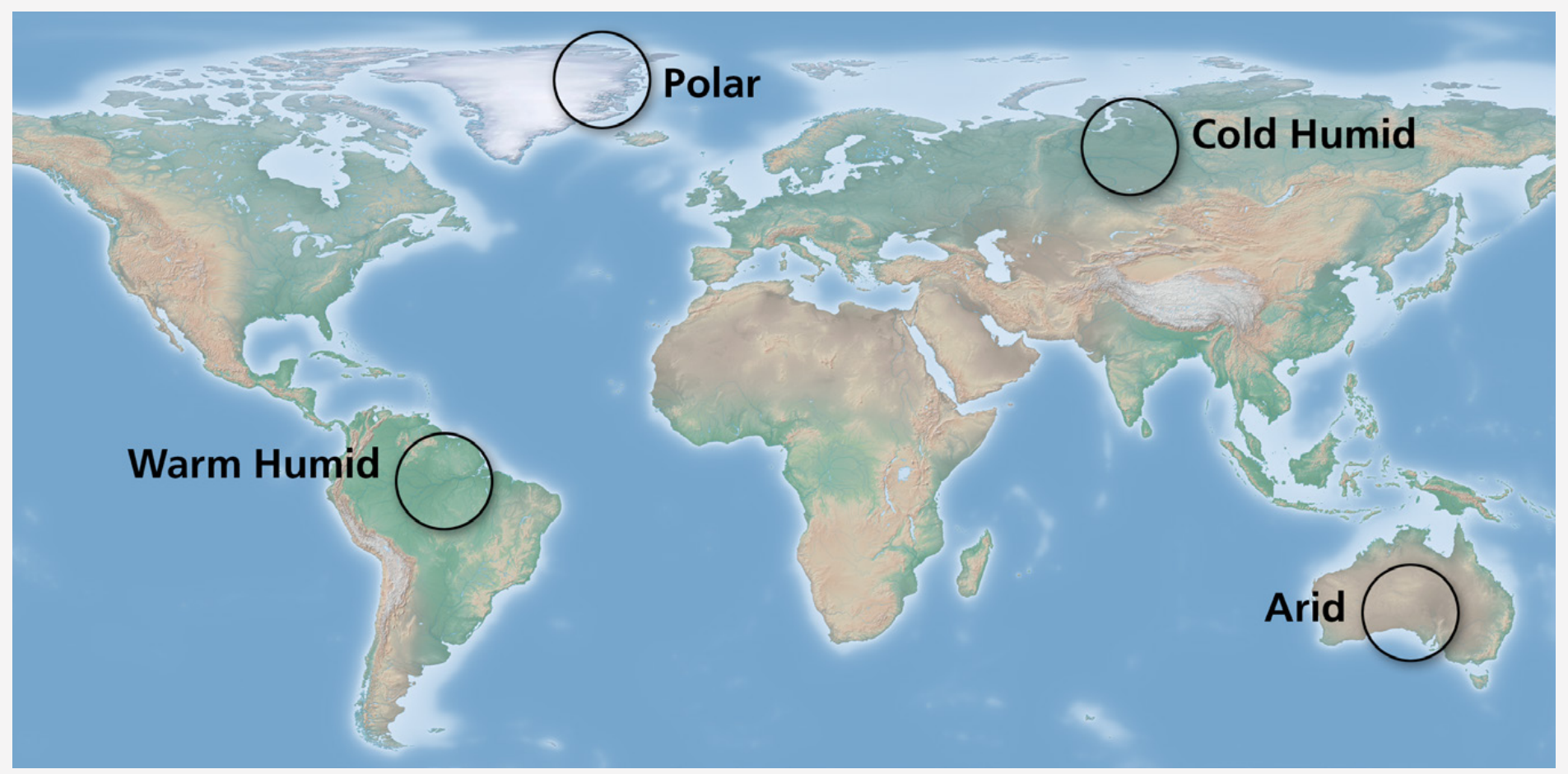

Figure 1: Cross-blended hypsometric tints have lowland colors that vary according to the generalized natural environment.

lowlands, such as the Amazon Basin, as warm yellow green (Figure 1). Alternative cross-blended hypsometric tint schemes for depicting these and other environmental regions are a possibility.

What motivated the development of cross-blended tints was the general concern among cartographers that casual readers of maps tend to confuse hypsometric tints with environmental factors, such as natural vegetation, land cover, or climate (Patton and Crawford 1978). The reason for this concern stems from the fact that many color schemes for hypsometric mapping do not align well with the theory of visual variables. After all, terrain elevation is an ordered sequence of values, which-in accordance with the theory of visual variables-is better mapped by varying color brightness than by varying hue or saturation. The potential for misinterpreting hypsometric tints is due to the use of varying hues, which - according to the theory of visual variables-is better at indicating nominal classes, such as vegetation types.

By representing lowlands with colors that depict both elevation and environmental factors ${ }^{1}$, the hope was that cross-blended hypsometric tints would better match how

1. In this text, the terms environment, environmental factors, or environmental phenomena refer to factors that influence the visual appearance of the landscape in a wide sense. Elevation is not considered an environmental influence in this context. many readers might interpret a physical map. For instance, if someone were to think that green represents vegetation and not low elevation, they would at least be partially right. Cross-blended tints are an attempt to design to the way people actually read maps instead of how cartographers wish they would.

\section{PRIOR RESEARCH}

Hypsometric tint research during the early and mid-twentieth century aimed at finding the best combination of colors for depicting higher and lower elevations. The research objective was to portray topography with as much of a three-dimensional appearance as possible on a flat sheet of paper (Patterson and Jenny 2011). The suggestion that people could confuse hypsometric tints for vegetation and other natural phenomena was put forward in the 1950s when Hal Shelton developed natural color maps as an alternative. He argued vociferously against using hypsometric tints on maps read by general audiences, calling them arbitrary (Patterson and Kelso 2004). Since then, the idea that perceptual problems might exist with hypsometric tints, especially among casual map users, has steadily grown in the cartographic community, based mostly on anecdotal evidence and assumptions. 
We know of only one cartography study that shows evidence that readers have trouble understanding hypsometric tints (Patton and Crawford 1978). Over 300 students in the United States were given a map of central Taiwan with Chinese characters to prevent learning about the study area by reading descriptive place names. Hypsometric tints were depicted on the map as stepped layers, and the map did not contain a shaded relief. Students looked at certain areas of the map indicated by Roman letters and answered what they thought was there in an accompanying survey, which offered two possible answers for each question. For example, "Point A is an area with: a) Many trees, b) Very few trees," or, "The highest land is: a) Point E, b) Point B."

Their study found that color hypsometric tints accurately transmitted data concerning elevation, but also transmitted

\section{STUDY DESIGN}

TO LEARN MORE about the perception of hypsometric tints, we designed a user study with markedly different maps and a different survey methodology from the 1978 Patton and Crawford study. The map used by Patton and Crawford contained place names and a legend indicating the meaning of the hypsometric tints-our test maps contain no place name labels or legend. Patton and Crawford used stepped hypsometric layers and did not include a shaded relief-our test maps represent terrain with blended hypsography and shaded relief. Patton and Crawford's respondents were children and young adults in the United States-we queried working-age adults living in the United States as well as Switzerland and Germany. Patton and Crawford asked multiple-choice questions-we made use of fill-in-the-blank questions that did not offer clues to participants about the meaning of map colors. While Patton and Crawford's study focused on testing reading and interpretation of hypsometric tints, our research aimed at testing the perception of hypsometric tints, attempting to answer the following questions:

- Do adult map readers perceive conventional hypsometric tints as representing elevation, environmental phenomena, or a combination of both?

- Do cross-blended hypsometric tints effectively represent both elevation and environment, as was their design intent? inaccurate and unintended information relating to vegetation, rainfall, and temperature. More importantly, green was often associated with dense vegetation and brown with sparse vegetation. This suggests that the idea behind creating cross-blended hypsometric tints has some validity.

If the Patton and Crawford study had a flaw, it was the possibility for introduced bias. The multiple-choice answers and map legend gave the test subjects direct clues as to what the map colors represented. They were not blank slates. Another issue was the population of test subjectsall were U.S. students from the 6th grade through college freshman. Left unanswered is how adults and those living beyond US shores perceive hypsometric tints.

- Which color is most strongly associated with elevation?

- Which color is most strongly associated with environment?

- Do Americans perceive hypsometric tints differently than Swiss and Germans?

\section{PARTICIPANTS}

All respondents in our study were working-age adults from the United States and two European countries, Switzerland and Germany. The participants had no known ties to the field of cartography.

The US participants were largely employees of the National Park Service at the Harpers Ferry Center in West Virginia. Their professions ranged from custodial to senior management, although most held administrative and clerical positions. A student volunteer approached the European participants on the streets of Zürich and Berlin. He was instructed to seek out a random cross section of people who had been educated in Swiss or German schools. Altogether, slightly more than 200 complete sets of responses were collected, divided about equally between the United States and Europe. ${ }^{2}$

\footnotetext{
2. In this text, "European" refers to the Swiss and German respondents. It is likely that considerable variety exists in how European nationalities read hypsometric tint maps. In no way should our wording imply that the Swiss and German respondents represent all of Europe.
} 

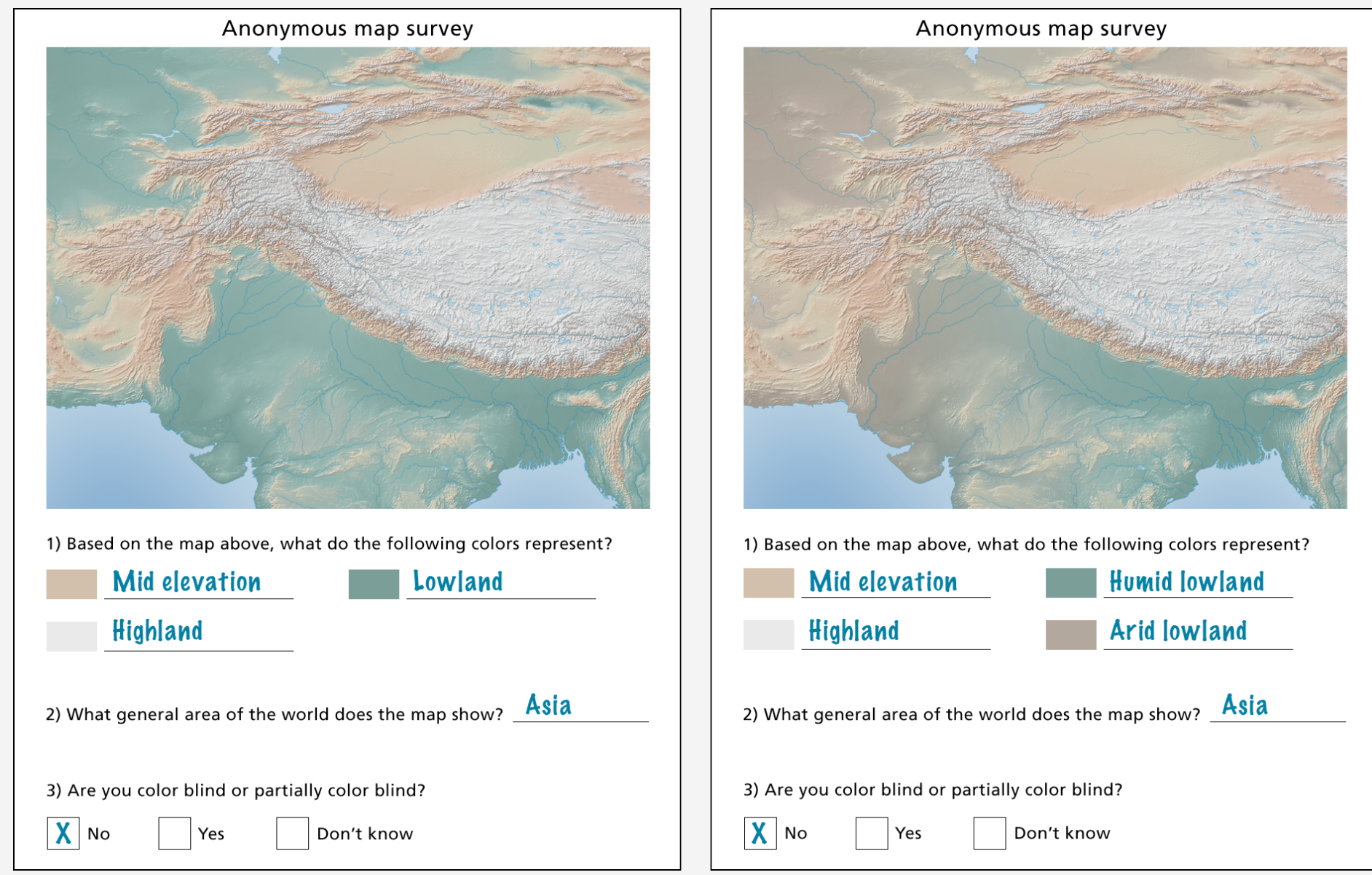

1) Based on the map above, what do the following colors represent?

\begin{tabular}{lll} 
Mid elevation & Humid lowland \\
Highland & Arid lowland \\
\hline
\end{tabular}

2) What general area of the world does the map show? Asia

3) Are you color blind or partially color blind?

$X$ No $\square$ Yes $\square$ Don't know

Figure 2: Survey form for conventional hypsometric tints (left) and cross-blended hypsometric tints (right). The cross-blended maps had an additional color (brown for arid lowland) to identify. Respondents had to write in their answers, here with the hoped-for "correct" responses shown in blue.

The survey was a single letter-size page with the test map at the top and three questions below, some of which had multiple parts. The anonymous questionnaire took only a minute or two to complete. The response rate was close to $100 \%$. Other than language, English in the United States and German in Europe, the questions were identical. For each of the geographic areas, $50 \%$ of the surveys had a test map with conventional hypsometric tints and 50\% had cross-blended hypsometric tints (Figure 2).

\section{TEST MAPS}

When creating the test maps, we employed a style commonly used for small-scale physical maps that combines hypsography and shaded relief. The cross-blended hypsometric tint map is an excerpt from the previously-mentioned base map available at NaturalEarthData.com. The conventional hypsometric tint map is identical to the cross-blended map except for the lowlands, which are exclusively green (Figure 2). Additional information typical of small-scale physical maps-coastlines, rivers, lakes, and a bit of ocean-appears on both test maps. Labels and a legend are absent from the maps so as not to inform respondents about the relationship between the physical geography and the colors that they had to identify. The maps show southern Asia without the recognizable southern tip of India. This area offered advantages: elevations that range greatly from the Ganges and Indus river lowlands upward to the Himalayas and Tibet. The terraced topographyplains, plateaus, and basins - make the hypsometric tints combined with shaded relief easier to discern. With arid lowlands in the west and humid lowlands in the east, the region is ideal for depiction with cross-blended hypsometric tints. Finally, asking respondents to identify the map location made it possible to test prior geographic knowledge as a factor influencing the results. 


\section{IDENTIFYING COLORS}

Much like creating a map legend, the participants were asked to write in their responses next to color swatches immediately below the test maps. The swatches were arranged out of sequence and discontinuously so as not to look like a typical elevation scale. There were three swatches for the three conventional hypsometric tints (green, pale orange-brown, and white) and four swatches for the four cross-blended tints (green, brown, pale orange-brown, and white).

The small amount of space available for the written answers encouraged brevity, and faster responses, and made the analysis of results easier. Because the hypsometric tints were found throughout the maps, some areas clearer than others, it was advantageous for the participants to think holistically when giving answers. Their choice of words provided raw, unfiltered data — a basic vocabulary — on how they perceived hypsometric tints.

\section{COLOR VISION DEFICIENCY}

Normal color vision was a prerequisite for the user study and four of the participants indicated having some degree of color vision deficiency, or "color blindness" as it is commonly known (Culp 2012). Disqualifying them reduced the number of accepted respondents from 217 to 213. This self-reported rate is about one half of that expected from the general population, males and females together. The 20 participants who indicated not knowing their color blindness status (18 Europeans and 2 Americans) were included in the study (Table 1).

\section{MAP LOCATION}

By asking "What general area of the world does the map show?" the intent was to learn whether prior geographic knowledge helped the participants identify map colors. For example, someone knowing that the map was of northern India and Central Asia might do better than a geographically-challenged individual.

The map location responses were evaluated much like answers on any school exam and given a grade of accurate, partially accurate, or inaccurate. Grading was generous. For example, someone giving the very general answer "Asia" received an accurate grade, although most people gave more detailed answers. Partially accurate responses usually included several countries that were on the map, for example, Afghanistan, India, and China, and at least one that wasn't, such as Russia or Thailand. The inaccurate answers were spectacularly off the mark and included Alaska, Austria, and Texas. Several people responded by writing, "don't know" or gave no answer, for which they received an inaccurate grade. Country and state answers were more common than physical feature answers, even though the test maps did not contain political borders.

Map location answers varied significantly between the American and European respondents (Figure 3). Other results from the study showed this American/European dichotomy, which will receive attention in a later section. The map location answers were identical regardless whether the test maps had conventional or cross-blended tints.

\section{Participants Responding Participants disqualified for color blindness}

Participants accepted for analysis

Hypsometric tint map:

$\begin{array}{lllll}\text { Conventional } & 109 & 2 & 107 & (50 \%) \\ \text { Cross-blended } & 108 & 2 & 106 & (50 \%)\end{array}$

Where taken

$\begin{array}{lllll}\text { Switzerland/Germany } & 110 & 2 & 108 & (51 \%) \\ \text { United States } & 107 & 2 & 105 & (49 \%) \\ \text { Total } & 217 & 4 & 213 \quad(100 \%)\end{array}$

Table 1: Number of responding, rejected, and accepted participants in the study. 


\section{METHODS AND RESULTS}

OBTAINING THE RESUlts as written answers offered an unfiltered expression of how participants perceived hypsometric tints on the test maps. From map to eyes to mind to hand: participant answers reveal a diverse vocabulary, ranging from terse to flowery and from general to technical. We employed two methods to make sense of this Babel of words.

\section{METHOD 1: GRADING}

Much like the map location answers described previously, the color answers identifying hypsometric tints were evaluated and received a grade of correct, partially correct, or wrong. The basis for grading was the "correct" color answers indicated by the blue text in Figure 2. For example, the gray-white hypsometric tint represents high elevation. If a person answered "highlands," they would receive a correct grade. However, if they answered, "snow," they would be wrong. An answer of "snowy highlands" would receive a partially correct grade. Pale orange-brown on the maps represents mid elevation. In this case giving "average height" as the answer was considered correct, "sandy terrain" wrong, and "tablelands" partially correct. Grading the cross-blended color answers required taking into account two variables. For example, with brown representing arid lowland, an answer of "lower/ drier areas" was graded as correct, "mountains" wrong, and "dry terrain" or "lowlands" partially correct. The color answers-there were 745 total from 213 surveys-were graded twice by Patterson on different dates months apart to assure consistent grading. The resulting grades were nearly identical on each occasion and the few differences that emerged were resolved in a consistent manner.

Looking at all responses, only $15 \%$ of the 745 color answers were correct (Figure 4). The large percentage of partially correct - such as "snowy highland"-(38\%) and wrong answers $(47 \%)$ indicates a common inability to identify hypsometric tints correctly. A lower percentage of cross-blended hypsometric tint answers were correct (11\%) compared
ALL SURVEYS

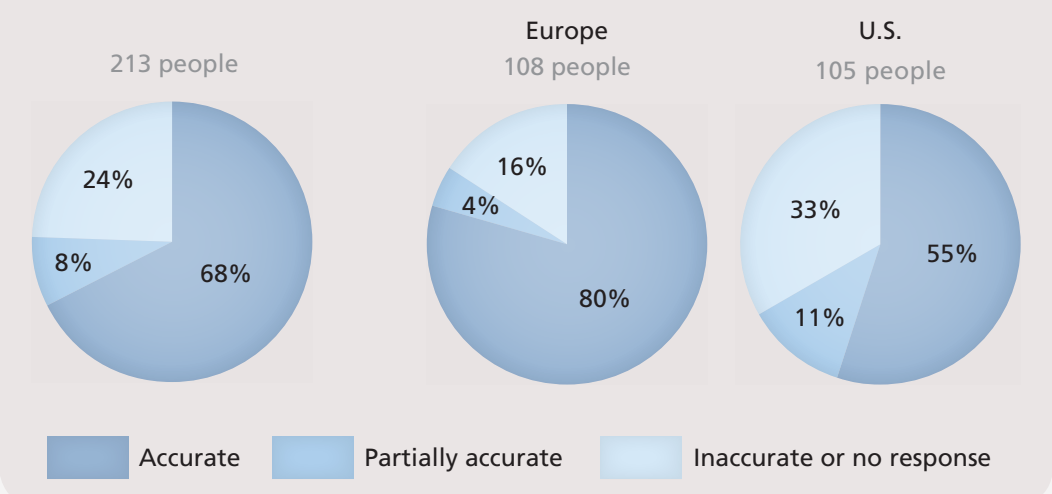

Figure 3: Map location answers. About one quarter of all participants gave inaccurate answers. The percentage of Americans giving inaccurate answers was twice that of Europeans.

\section{ALL SURVEYS}

213 people giving

745 color answers

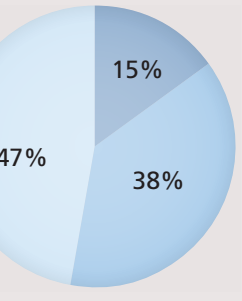

GRADE:
Correct
HYPSOMETRIC TINT MAP
Conventional

107 people giving 321 color answers

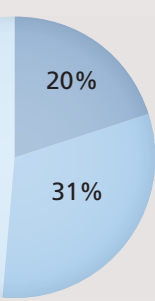

Partially correct
Cross-blended

106 people giving 424 color answers

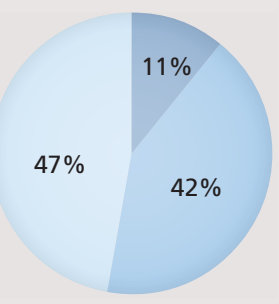

Wrong or no response
Figure 4: Graded color answers.

to conventional hypsometric tints (20\%). This difference may have resulted from cross-blended tints representing two types of information-elevation and environmentlowering the chances for correct answers by one half.

Where the surveys were taken-United States or Switzerland/Germany - and the map location answers may have influenced the color answer grades (Figure 5). A much higher percentage of Europeans identified the hypsometric tints correctly (22\%) compared to Americans $(8 \%)$ and the inverse was true for wrong answers. People answering the map location question correctly were also more likely to provide correct color answers than those who did not, $16 \%$ to $10 \%$, suggesting that geographic 
knowledge had a modest positive influence on reading hypsometric tints correctly.

A closer examination of the data reveals that Europeans who answered the map location question inaccurately also fared poorly on their color answers with 44\% receiving wrong grades, up from $28 \%$ wrong grades for all Europeans. Conversely, Americans answering the map location correctly received little benefit to their color answer grades. However, the low numbers in these subset populations (11 and 13 people, respectively) argues against drawing firm conclusions.

\section{METHOD 2: CLASSIFICATION}

Aside from being right or wrong, a rather blunt measure, the words chosen by the respondents may provide nuanced insights on perceived map colors. A classification system helped bring order to the disparate words and terms collected from the surveys.

Since the questions were about hypsometric tints, classifying words relating to elevation was the first consideration. Doing this proved problematic because many of the answers had ambiguous meanings describing more than just elevation. For example, plateau, a common answer, defines land that is both elevated and flat. There was no way of knowing which of these definitions, or possibly both, a respondent had in mind. To avoid having to guess about the respondents' intent, the answers were classified more broadly as follows: answers.

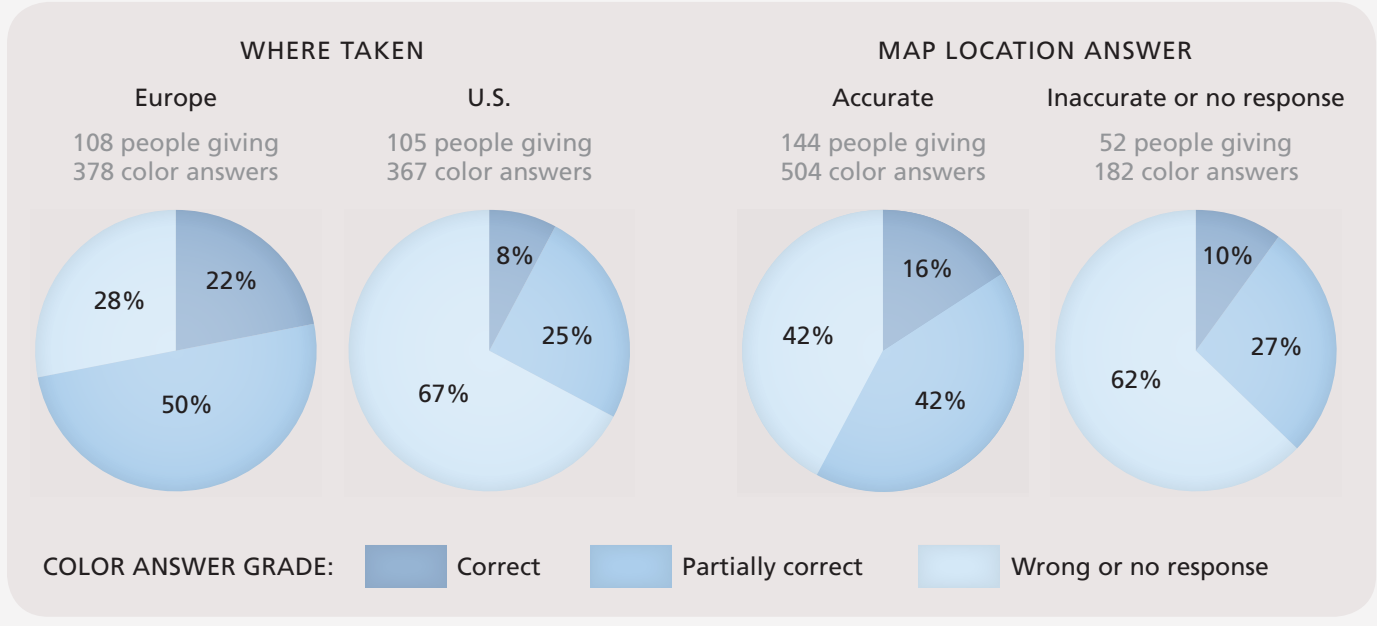

Figure 5: Graded color answers according to where the surveys were taken and the map location

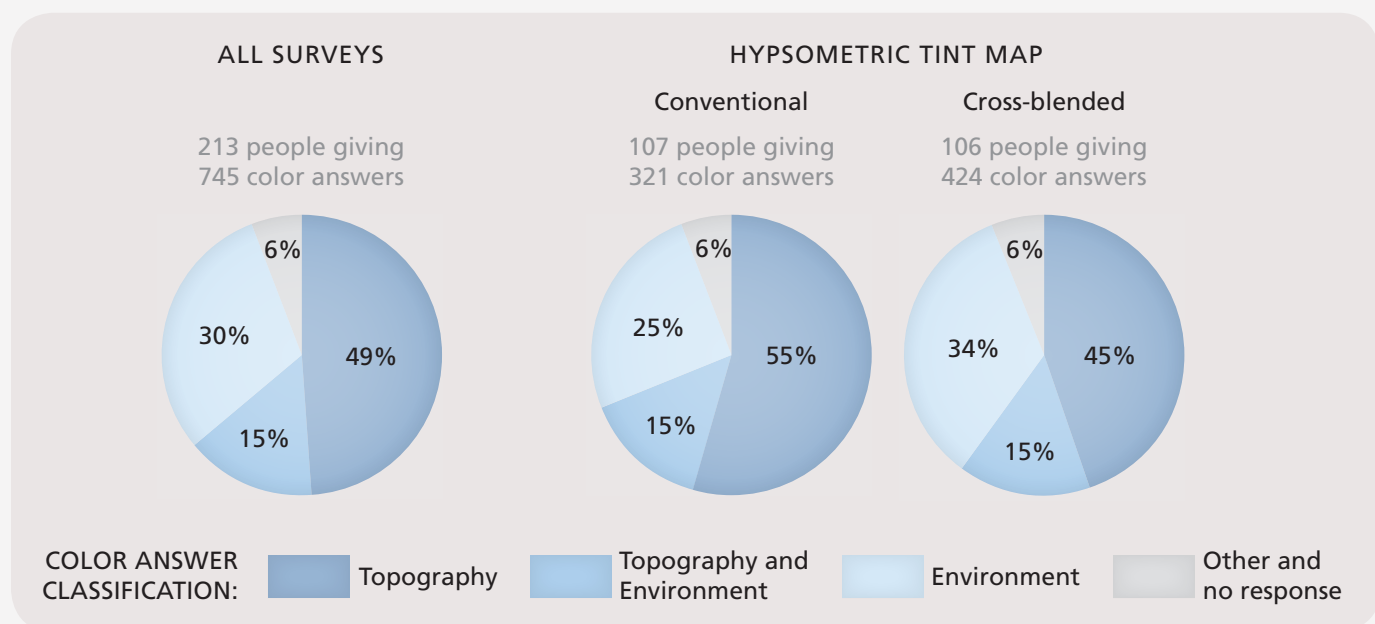

Figure 6: The classified color answers by hypsometric tint type.

1. Topography: words and terms describing elevation and/or terrain type. Examples include bighland, mountains, low plains, and rugged uplands.

2. Environment: words and terms describing vegetation, land cover, and/or climate. Examples include forest, cropland, snow, and arid land.

3. Topography and Environment: words and terms describing both of the above. Examples include snow-capped mountains, lowland forest, and cold mountains.

4. Other and no response: ambiguous words and terms. Examples include land and green land. 


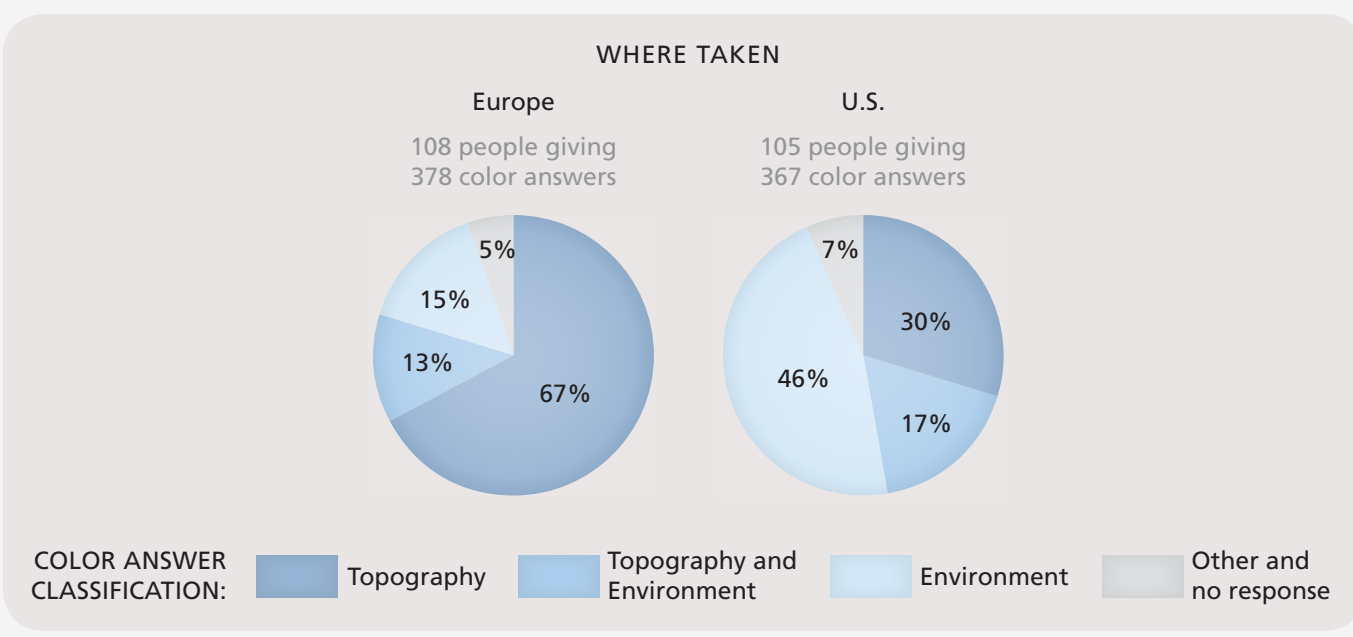

Figure 7: Classified color answers according to where the surveys were taken.
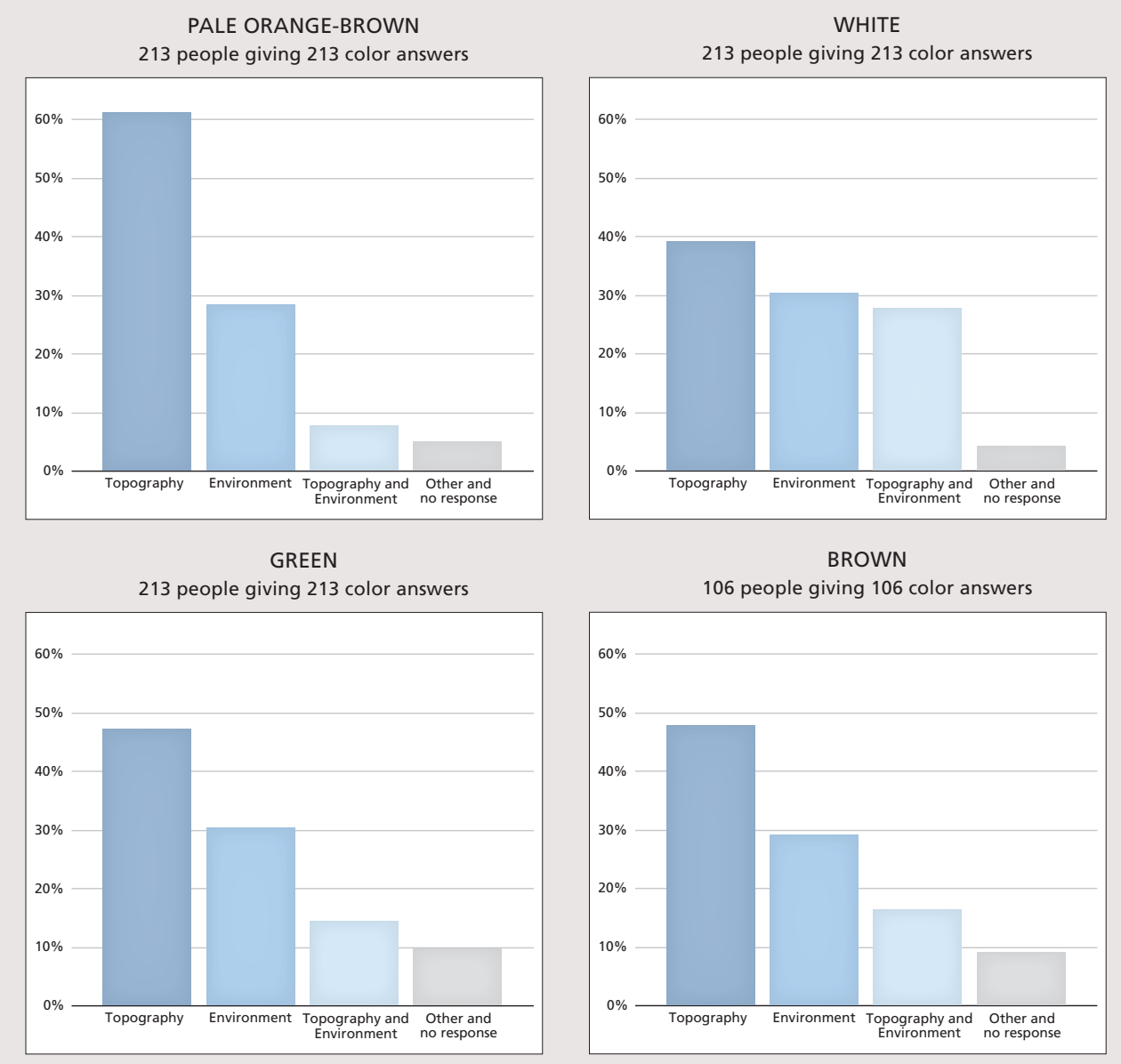

Figure 8: Classified color answers for each hypsometric tint.

After classifying the answers twice as a check for consistency, the results show $49 \%$ of the total answers related to topography, $30 \%$ to environment, and $15 \%$ to a combination of both (Figure 6). That nearly half $(30 \%+15 \%)$ of the answers describe environmental phenomena at least partially points out again the mixed perceptions many people have of hypsometric tints. Crossblended hypsometric tints registered more answers in the environment classification than conventional hypsometric tints, $34 \%$ to $25 \%$. Since cross-blended tints are intended to depict topography and environment, this result is somewhat encouraging.

The location of the survey seems to influence results (Figure 7 ). The majority of Europeans gave topography answers (67\%) compared to only a minority of Americans (30\%). Conversely, 46\% of Americans and 15\% of Europeans favored environment answers. These opposite perceptions of hypsometric tints by Europeans and Americans cancel each other in the aggregated results shown in Figure 6.

The test maps contain a mix of pale brown-orange, white, green, and brown hypsometric tints. The classified answers given for each of these colors reveal 
additional perceptual preferences (Figure 8). The pale brown-orange color is the color most strongly associated with topography, with $62 \%$ of the answers falling in that classification. White is the color most classified as environment (31\%), or mixed topography and environment (27\%). The classification of green and brown responses are between these extremes and nearly identical to one another.

The wide divide between European and American hypsometric tint perceptions becomes apparent in a chart showing the percentage of responses classified as solely environment for each hypsometric tint (Figure 9). Those giving solely environment answers for pale orange-brown included $50 \%$ of the Americans and $0 \%$ of the Europeans. For green, 52\% of Americans recorded solely environment answers, as did $11 \%$ of Europeans. Brown registered a similar percentage of environment answers for Europeans and Americans, but for different reasons. More than any other color, Europeans identified brown as solely representing environment, while Americans identified brown as the least environmental color. The divide between Europeans and Americans is also evident in the colors identified as solely topography (Figure 10). Europeans unanimously identified pale orange-brown with topography and over 50 percent of the answers identified the other colors as representing topography. Americans by contrast were about half as likely as Europeans to identify any of the colors as topography.

\section{SUMMARY OF RESULTS}

Below are brief answers to the basic questions about hypsometric tints that framed the design of this study. These are followed by a broader discussion of the complex issues revealed by the collected responses.

Q: Do adult map readers perceive conventional hypsometric tints as representing elevation, environmental phenomena, or a combination of both?

A: The respondents generally described hypsometric tints as a combination of topography (elevation and land forms) and environmental phenomena.

Q: Do cross-blended hypsometric tints effectively represent both elevation and environment, as was their design intent?

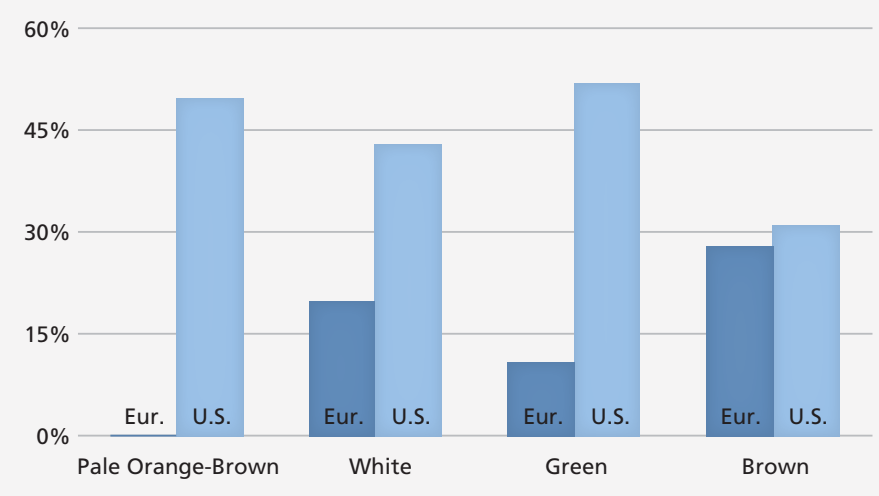

Figure 9: Percentage of color answers classified as solely environment for each hypsometric tint by Europeans and Americans.

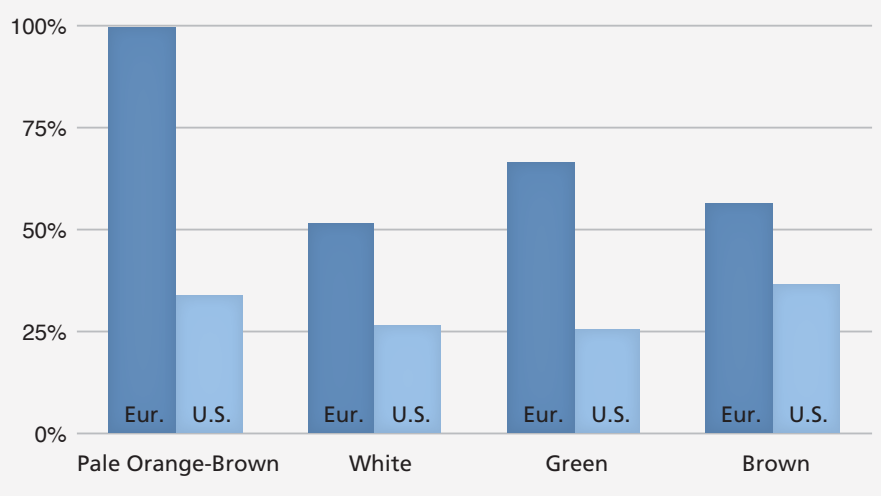

Figure 10: Percentage of color answers classified as solely topography for each hypsometric tint by Europeans and Americans.

A: The results were mixed. Cross-blended hypsometric tints were no more effective in this regard than conventional hypsometric tints.

Q: Which color is most strongly associated with elevation?

A: Pale orange-brown.

Q: Which color is most strongly associated with environment?

A: Green, followed closely by white.

Q: Do Americans perceive hypsometric tints differently than Swiss and Germans? 
A: Americans described hypsometric tints as environmental phenomena more often than did Europeans. A majority of Americans described green as representing environmental phenomena. Europeans unanimously described pale orange-brown as representing topographic phenomena.

\section{DISCUSSION}

THis sTUDY, which was motivated by the desire to evaluate cross-blended hypsometric tints, yielded insights on those tints and on hypsometric tints in general. It supports the previous research by Patton and Crawford (1978) who found that map users frequently confuse conventional hypsometric tints with environmental phenomena, such as vegetation and climate. The Patton and Crawford study tested students in the United States. This study tested adults in the United States and Switzerland/Germany, broadening the demographic and geographic sample population. It also employed a different testing methodology. Instead of multiple-choice questions, respondents had to write short answers identifying what hypsometric tints on the test maps represented.

What emerged from the study were distinctly different responses from Americans and Europeans. Americans were far more likely to identify hypsometric tints with environmental factors. By contrast, Europeans overwhelmingly identified the same tints as relating to topography. An explanation for these perceptual differences could be education-Swiss and German students receive training on reading hypsometric tints while American students generally do not. In addition, many maps and atlases published in Germany, such as the commonly-used Diercke school atlas by Westermann, favor red tints at high elevations, which could help explain why all Swiss and German study participants associated pale orange brown with topography. Another difference between these two populations was the map location question, answered accurately by $80 \%$ of Europeans and 55\% of Americans. This finding generally agrees with those of the National Geographic-Roper Survey of Geographic Literacy (2006).

This study cannot be definitive on cross-blended hypsometric tints. This scheme that uses brown to represent arid lowlands and green to represent humid lowlands went largely undetected by the respondents. Only 5\% of their answers for brown were correct and 23\% of answers for green were correct. Taking all of the cross-blended tints together, Americans were more likely than Europeans to identify them with mixed topography and environment answers. Nevertheless, maps that employ cross-blended hypsometric tints should include a legend to avoid confusion about what they represent. The need for a map legend also applies to conventional hypsometric tints.

Differences existed in the responses to individual hypsometric tints. Taking into account all Americans and Europeans, white had the most mixed topography and environment answers. The majority of Americans (52\%) answered that green represented only the environment. A remarkable $100 \%$ of Europeans gave answers indicating that pale orange-brown represented only topography. The brown answers were inconclusive.

Collecting written responses proved a workable method for testing users' perceptions of maps. Although the responses were sometimes messy and involved considerable time to analyze, they are assumed to provide an insight into what the test subjects were thinking. Not one person identified the hypsometric tints as anything other than physical geography phenomena-on that most elementary level the hypsometric tints succeeded.

The choice of words used to answer the questions was revealing. Nearly everyone described white on the maps with some combination of these terms: mountain, cold, snowy, ice, glacier, high elevation, and alpine. Several Americans used the somewhat unusual but logical term snow caps. Green was overwhelmingly described with words such as lowland, plains, vegetation, forest, grass, and agriculture. These words demonstrate the strong connection between color, nature, and language. As examples, the most common high mountain name worldwide regardless of the language is white or snow (Julyan 1984). And the etymology of green is from the west Germanic word groeni, meaning grass or to grow, an ancient association that has apparently persisted to today among the respondents.

An unexpected result was inconsistent answers by individuals. The majority of respondents (62\%) identified hypsometric tints with a heterogeneous mix of topographic and environmental answers. Instead of seeing the map colors as 
representing a continuum of related data, their responses were unsystematic. In other words, the mindset of the map author differed from that of the people reading it. This is another argument for always identifying hypsometric tints in a map legend.

With this study we can now say with more certainty that confusion exists over the meaning of hypsometric tintsconventional and cross-blended alike-especially among American audiences. This finding supports the recent trend by cartographers to produce natural color maps that combine land cover and shaded relief, Natural Earth being a well-known example (Patterson and Kelso 2004). But are these natural color maps a better alternative to hypsometric tints? Studies by Phillips et al. (1975) and Philips (1979) suggest the effectiveness of hypsometric tints for representing the third dimension (elevation) on a flat map,

\section{ACKNOWLEDGMENTS}

The authors wish to thank Mario Spengler, Beuth Hochschule für Technik Berlin, for asking strangers on the streets of Berlin and Zürich to participate in the study, translating their written responses from German to

\section{REFERENCES}

Culp, G. M. 2012. “Increasing Accessibility for Map Readers with Acquired and Inherited Colour Vision Deficiencies: A Re-Colouring Algorithm for Maps.” The Cartographic Journal 49(4): 302-311.

Julyan, R. H. 1984. Mountain Names. Seattle: Mountaineers.

Kretschmer, I. 1986. "Höhenschichtenkarte." Lexikon zur Geschichte der Kartographie, edited by I. Kretschmer, J. Dörflinger, and F. Wawrik, 306-308. Vienna: Deuticke.

1988. "The first and second Austrian school of layered relief maps in the nineteenth and early twentieth centuries." Imago Mundi 40(1): 9-14.

Natural Earth Data. Accessed February 18, 2013. http:// www.naturalearthdata.com.

2006 National Geographic-Roper Survey of Geographic Literacy. Accessed February 18, 2013. http://www. nationalgeographic.com/roper2006/findings.html. an advantage that is perhaps diminished with the use of natural colors. Another study comparing hypsometric tints to natural color maps would seem the logical next step in this investigation.

Other avenues for hypsometric tint research include stepped versus blended color schemes, test maps with fictional landscapes to avoid any ambiguity introduced by prior knowledge, more realistic test maps with place name labels and spot elevations, and the wide-open arena of color preferences. Testing hypsometric tint maps with and without legends, to gauge if having a legend improves map reading ability, is also worth pursuing. It is a given that cartographers will continue making hypsometric tint maps for decades to come. More studies of this popular technique can only benefit those who read our maps.

English, and compiling the results. We appreciate the 217 people who gave a couple minutes of their time to answer our questions.

Patterson, T. and B. Jenny. 2011. “The Development and Rationale of Cross-blended Hypsometric Tints." Cartographic Perspectives 69: 31-45.

Patterson, T. and N. V. Kelso. 2004. "Hal Shelton Revisited: Designing and Producing Natural-Color Maps with Satellite Land Cover Data." Cartographic Perspectives 47: 28-55.

_. 2009. "Natural Earth Vector." Cartographic Perspectives 64: 45-50.

Patton, J. C. and P. V. Crawford. 1978. “The Perception of Hypsometric Colours.” The Cartographic Journal 14(2): 115-127.

Philips, R. J., A. De Lucia, and N. Skelton. 1975. "Some Objective Tests of the Legibility of Relief Maps.” The Cartographic Journal 12(1): 39-46.

Philips, R. J., 1979. “An Experiment with Contour Lines.” The Cartographic Journal 16(2): 72-76. 
